\title{
HUMOR, IRONIA E INTERTEXTUALIDADE: PRODUÇÃO E CONSUMO DA SÉRIE NARCOS NO FACEBOOK
}

Humor, ironía y intertextualidad: producción y consumo de la serie Narcos en Facebook

\section{Humor, irony and intertextuality: production and consumption of the series Narcos on Facebook}

\section{Beatriz Braga Bezerra}

Doutoranda em comunicação e práticas do consumo no Programa de Pós-Graduação da Escola Superior de Propaganda e Marketing (PPGCOM/ESPM). Mestre em comunicação pelo Programa de Pós-Graduação da Universidade Federal de Pernambuco (PPGCOM/UFPE).

Email: beatriz.braga@hotmail.com

\section{Rafael Ofemann}

Mestrando em comunicação e práticas do consumo no Programa de Pós-Graduação da Escola Superior de Propaganda e Marketing (PPGCOM/ESPM).

Email: rafael.ofemann@gmail.com

RESUMO As webséries já se consolidam como prática cultural contemporânea, estruturando novos modelos de negócio e de consumo no setor audiovisual. Objetivamos analisar a página de Narcos no Facebook buscando compreender sua atuação para informar e cativar o público diante de um cenário de múltiplas plataformas e viralização de conteúdos.

PALAVRAS-CHAVE Comunicação e consumo, Narrativas audiovisuais, Narcos, Facebook.

RESUMEN Las serie web ya consolidado como una práctica cultural contemporânea y ha desarrollado nuevos modelos de negocio y el consumo en el sector audiovisual. Examinaremos la página Narcos en Facebook tratando de comprender sus actividades para informar y comprometer al público ante un contexto de varias plataformas y viralización de contenidos.

PALABRAS CLAVE Comunicación y consumo, Narrativas audiovisuales, Narcos, Facebook.

ABSTRACT Webseries have been established as a contemporary cultural practice structuring new business models and consumption habits in the audiovisual sector. We aimed at analyzing the Narcos page on Facebook trying to understand its activities to inform and engage the public in a environment of multiple platforms and viralization content.

KEYWORDS Communication and consumption, Audiovisual narratives, Narcos, Facebook.

Trabalho apresentado no GT 10 - Televisão e Contemporaneidade, no III Congresso Internacional Red INAV. 


\section{INTRODUÇÃO}

O consumo e a produção de narrativas audiovisuais há muito quebraram os limites dos espaços tradicionais de exibição - as salas de cinema ou mesmo as telas de TV -, ao adentrarem a Internet e promoverem uma já extensa produção específica para o ambiente digital. As webséries se consolidaram como prática cultural contemporânea, estruturando novos modelos de negócio e de consumo midiático. As séries originais da empresa estadunidense Netflix, serviço de televisão por streaming, encaixam-se nessa categoria de narrativas audiovisuais produzidas para ambientes digitais. Como forma de divulgação, o canal tem forte presença nas redes sociais digitais, com perfis próprios para cada série.

Neste artigo, investigaremos a página de Narcos no Facebook, série original lançada em agosto de 2015, que conta a história do traficante colombiano Pablo Escobar e sua ascensão com o Cartel de Medellín. O perfil da série na rede social utiliza humor, ironia e diversas intertextualidades no tratamento das mensagens com as quais procura informar e cativar o público. Objetivamos revelar as lógicas de produção e as estratégias midiáticas utilizadas na página frente à dispersão da atenção por parte do público, que hoje se desdobra em diversas plataformas, bem como no cenário de viralização de conteúdos nas redes sociais digitais. Para isso, selecionaremos para análise seis postagens da página relevantes para os aspectos aqui pontuados.

Utilizaremos como aportes teóricos os argumentos de: Jenkins (2009) sobre convergência midiática e a espalhabilidade de conteúdos on-line; Santaella (2003 e 2006) e Lemos (2003) sobre as eras socioculturais e fases da cibercultura; sobre humor, ironia e intertextualidades, recorremos a Propp (1992), Bakhtin (1999) e Kristeva (1974), além das referências diretas aos estudos sobre redes sociais digitais de Castro (2012), Recuero (2009) e Sibilia (2008), entre outros.

\section{CIBERCULTURA, CONVERGÊNCIA MIDIÁTICA E ESPALHABILIDADE}

Santaella (2003, p. 26) entende que os processos comunicacionais na sociedade se transformaram e se complexificaram com o passar do tempo, de modo que podemos organizar essas mudanças em seis eras distintas: a cultura oral, a cultura escrita, a cultura impressa, a cultura de massa, a cultura das mídias e a cibercultura. De início, os povos comunicavam-se apenas oralmente e, depois, criaram sistemas de representação gráfica; a chegada da cultura impressa garantiu a reprodutibilidade dos conteúdos, e a cultura de massa potencializou essa disseminação com os meios de comunicação (jornal, rádio, televisão). A cultura das mídias permitiu a manipulação e a edição dos materiais e também a emissão por parte do público; e, com a cibercultura, os internautas podem se posicionar e interagir em escala mundial, além de portarem em um único hardware diversas funções que antes eram realizadas de modo segmentado em vários aparelhos.

Embora as eras culturais tenham sido postas em sequência cronológica, a autora defende que isso não significa que um período elimine o anterior, mas que eles coexistem. "Há sempre um processo cumulativo de complexificação: uma nova formação comunicativa e cultural vai se integrando na anterior, provocando nela reajustamentos e refuncionalizações” (Santaella, 2006, p. 25). 
Jenkins (2009) denomina de convergência midiática essa cooperação das mídias no intuito de ampliar as narrativas em cada conteúdo veiculado e impulsionar novos hábitos de consumo, sobretudo nos ambientes digitais. Para além da tecnologia, "a convergência representa uma transformação cultural, à medida que consumidores são incentivados a procurar novas informações e fazer conexões em meio a conteúdos de mídia dispersos” (Ibidem, p. 30).

A convergência ocorre dentro dos cérebros de consumidores individuais e em suas interações sociais com outros. Cada um de nós constrói a própria mitologia pessoal, a partir de pedaços e fragmentos de informações extraídos do fluxo midiático e transformados em recursos através dos quais compreendemos nossa vida cotidiana. Por haver mais informações sobre determinado assunto do que alguém possa guardar na cabeça, há um incentivo extra para que conversemos entre nós sobre a mídia que consumimos. Essas conversas geram um burburinho cada vez mais valorizado pelo mercado das mídias. O consumo tornou-se um processo coletivo. (Ibidem, p. 30)

Dessa forma, o processo de convergência altera o modo de produção da indústria midiática e a maneira como o público irá se relacionar com os conteúdos informativos e de entretenimento, a partir de vários pontos de contato.

A convergência representa uma mudança de paradigma - um deslocamento de conteúdo de mídia específico em direção a um conteúdo que flui por vários canais, em direção a uma elevada interdependência de sistemas de comunicação, em direção a múltiplos modos de acesso a conteúdos de mídia e em direção a relações cada vez mais complexas entre a mídia corporativa, de cima para baixo, e a cultura participativa, de baixo para cima. (Jenkins, 2009, p. 325)

Lemos (2003) aponta três premissas da cibercultura: a liberação do polo de emissão, a conexão generalizada e a reconfiguração. Com a liberação da emissão, instaura-se a comunicação bidirecional, em que os consumidores se tornam produtores e disseminadores de conteúdo. Com a segunda premissa, evidencia-se a multiplicidade de aparelhos portáteis, facilitando o acesso ao universo digital. E, com a reconfiguração, confirma-se a convergência defendida por Jenkins (2009).

A cibercultura é a cultura contemporânea marcada pelas tecnologias digitais. Vivemos já a cibercultura. Ela não é o futuro que vai chegar, mas o nosso presente (home banking, cartões inteligentes, celulares, palms, pages, voto eletrônico, imposto de renda via rede, entre outros). Trata-se assim de escapar, seja de um determinismo técnico, seja de um determinismo social. A cibercultura representa a cultura contemporânea, sendo consequência direta da evolução da cultura técnica moderna. (Lemos, 2003, p. 11)

Na cibercultura, os consumidores tensionam o poder de comunicação antes restrito a conglomerados de mídia, pois, ao possuírem espaço para divulgação e interação em escala global, assumem papel equivalente. Jenkins, Green e Ford (2014) explicam que ocorre uma mudança de 
distribuição para circulação de conteúdos, visto que os internautas acabam por modelar os fluxos de mídia.

O público não é mais visto como simplesmente um grupo de consumidores de mensagens pré-construídas, mas como pessoas que estão moldando, compartilhando, reconfigurando e remixando conteúdos de mídia de maneiras que não poderiam ter sido imaginadas antes. E estão fazendo isso não como indivíduos isolados, mas como integrantes de comunidades mais amplas e de redes que lhes permitem propagar conteúdos muito além de sua vizinhança geográfica. (Ibidem, p. 24)

Para os autores, com essa postura ativa dos consumidores, os produtores tradicionais de mídia e gestores de marcas perceberam a urgente demanda por uma interação ativa com o público. Compreender o que é interessante - "propagável” ou "espalhável” - para esses visitantes, quais publicações são mais populares nos ambientes digitais e o que os motiva a compartilhar materiais em suas redes sociais tornouse ponto de partida no desenvolvimento de estratégias de comunicação (Jenkins; Green; Ford, 2014, p. 26).

\section{PRODUÇÃO E CONSUMO NAS REDES SOCIAIS DIGITAIS}

Lévy (2004) esclarece que o crescimento do ciberespaço se deu em função de três princípios básicos: a interconexão, a criação de comunidades virtuais e a inteligência coletiva. A interconexão, em especial, é a "pulsão mais forte”. Segundo o teórico, "para a cibercultura, a conexão é sempre preferível ao isolamento. A conexão é um bem em si” (Ibidem, p. 129). Partindo da interconexão, o segundo princípio indica a criação das comunidades nos ambientes digitais.

Uma comunidade virtual é construída sobre as afinidades de interesses, de conhecimentos, sobre projetos mútuos, em um processo de cooperação ou de troca, tudo isso independentemente das proximidades geográficas e das filiações institucionais. (Ibidem, p. 130)

Para Castells (2004, p. 15) as redes podem ser definidas como um conjunto de nós conectados: "as redes são formas muito antigas da atividade humana, mas atualmente essas redes ganharam uma nova vida, ao converterem-se em redes de informação, impulsionadas pela internet”. Castro e Junqueira (2014, p. 155) ressaltam que a Internet não é apenas a tecnologia; "é um artefato cultural, um objeto sociotécnico. Sua extraordinária plasticidade e sua arquitetura aberta e multicentrada favorecem diferentes modos de apropriação social”. É um engano pensar, para os autores, que a Internet exerce somente papel instrumental e que seu universo é uma "cultura à parte” (Ibidem, p. 156).

Recuero (2009, p. 24) explica que, com a Internet, a sociedade passou a se expressar na rede de computadores, e essas interações constroem um rastro valioso para a compreensão dos grupos sociais. Segundo a autora, as redes sociais são compostas por atores e suas conexões. Esses vínculos entre os internautas consolidam uma estrutura social a partir 
dos padrões de conexão estabelecidos, de modo que não é possível isolar os componentes.

No ciberespaço, os atores engendram um "processo permanente de construção e expressão de identidade" por meio de páginas pessoais como os weblogs (blogs) e perfis em sites de redes sociais (Ibidem, p. 26). Ao tomar contato com esses ambientes digitais e alimentá-los com informações, os internautas transpõem o "eu" para esse universo. Sibilia (2008) acredita que a sociedade contemporânea tem necessidade de se expor no ciberespaço.

Milhões de usuários de todo o planeta - gente "comum", precisamente como eu ou você - têm se apropriado das diversas ferramentas disponíveis on-line, que não cessam de surgir e se expandir, e as utilizam para expor publicamente a sua intimidade. Gerou-se assim, um verdadeiro festival de "vidas privadas", que se oferecem despudoradamente aos olhares do mundo inteiro. As confissões diárias de você, eu e todos nós estão aí, em palavras e imagens, à disposição de quem quiser bisbilhotá-las; basta apenas um clique do mouse. E, de fato, tanto você como eu e todos nós costumamos dar esse clique. (Sibilia, 2008, p. 27)

Constroem-se identidades a todo momento, mas nem sempre as informações compartilhadas coincidem com a realidade. Baym (2010, p. 105) defende que, com a Internet, as pessoas descartam a ideia de que uma identidade está presa a um corpo físico e criam dados fictícios nos ambientes digitais. "As pessoas certamente podem mentir na vida real, mas é difícil fingir ter outro sexo ou outra idade”, afirma Baym (Ibidem, p. 106).

A urgência de produzir e consumir informações pessoais pontuada por Sibilia (2008) acumula-se em páginas individuais, e pode ser visualizada no rastro que os atores deixam em suas interações e conexões, incluindo os perfis falsos. Comentários, postagens e avaliações em perfis institucionais tendem a permanecer visíveis até quando alguém os apague (Recuero, 2009, p. 30), e isso constitui extenso material para estudo de nichos de mercado, sobretudo para anunciantes.

De acordo com Ford (2014), as empresas estão investindo em uma variedade de ferramentas de monitoramento para investigar o que as pessoas estão falando de suas marcas na Internet. Essas ferramentas quantificam as conversas dos consumidores e as classificam em função do tom da conversa, se positivo, negativo ou neutro. Mas o autor alerta que não se trata de vigiar os ambientes digitais em busca de citações às marcas, e sim de ouvir de fato o que os consumidores estão falando no contexto de cada situação, prestando atenção aos detalhes.

Isso significa que, além de "oferecer conteúdo relevante que seja capaz de capturar a atenção sempre fugaz do cliente em potencial”, como pontua Castro (2012, p. 134), é necessário manter-se em diálogo com os internautas, visando entender suas demandas e aprimorar os produtos e serviços fornecidos. Para Lévy (2001, p. 113), uma boa estratégia de comunicação nos ambientes digitais deve "atrair, canalizar, estabilizar a atenção. E ocorre que a melhor forma de polarizar a atenção, em um mercado tão livre e aberto quanto o ciberespaço, é prestar serviço, escutar exatamente o que querem as pessoas e dar isso a elas"; caso contrário, elas se dispersarão rapidamente. Para Ford (2014), é preciso 
se colocar no lugar dos consumidores e se tornar responsável por eles; é preciso ter empatia.

\section{HUMOR, IRONIA E INTERTEXTUALIDADES}

No intuito de compreender como consumimos histórias na contemporaneidade, Jenkins (2009, p. 169) explica que, longe do "colapso da narrativa" alardeada por críticos de cinema, estaríamos em contato com novos modelos e estruturas narrativas, "que criam complexidade ao expandirem a extensão de possibilidades narrativas, em vez de seguirem um único caminho, com começo, meio e fim”. Estudando a relação dos fãs com séries e filmes nos ambientes digitais, o autor argumenta:

Cada vez mais, as narrativas estão se tornando a arte da construção de universos, à medida que os artistas criam ambientes atraentes que não podem ser completamente explorados ou esgotados em uma única obra, ou mesmo em uma única mídia. O universo é maior do que o filme, maior, até, do que a franquia - já que as especulações e elaborações dos fãs também expandem o universo em várias direções. (Ibidem, p. 161-162)

O ciberespaço, por meio de sites, páginas de redes sociais e outros espaços, proporciona aos internautas um profundo repositório de informações sobre filmes, livros, séries e outros produtos de entretenimento. As comunidades de fãs criam fóruns para debates e verdadeiras investigações sobre as tramas ficcionais que admiram, vide os estudos de Jenkins (2009) sobre as comunidades em torno do reality show American Idol e da série Heroes.

De modo semelhante ao desenvolvido por profissionais de marketing para gerir páginas institucionais na Internet, perfis de produtos de entretenimento nas redes sociais - aqui analisaremos em específico um perfil no Facebook - empenham-se em fortalecer o relacionamento com os consumidores por meio de postagens, enquetes e ações promocionais. Promovendo debates ou incentivando o consumo de produtos licenciados, os perfis de filmes e séries buscam construir uma reputação a longo prazo junto do público - expandindo "investimentos emocionais, sociais e intelectuais do consumidor" (Jenkins, 2009, p. 98) -, assumindo o papel estratégico de comunicação da marca no ciberespaço.

No intuito de se aproximar do público, o uso de humor, ironia e intertextualidades na comunicação dessas páginas pode ser entendido como uma estratégia de complexificação das próprias narrativas de entretenimento que representam, sejam séries, filmes ou outros produtos. Para Acserald (2004, p. 139), o uso do humor "tem como função diminuir - não anular nem disfarçar - o impacto da tragédia de vida e morte”. Segundo o autor, nenhum tema, nem mesma a morte, é impossível para o humor. "Quanto mais cheio de pompa, quanto mais sério, quanto mais dramático, tanto mais humorístico será” (Ibidem, p. 140).

Propp (1992) explica que o ser humano pode reagir de modo muito diverso nas situações do cotidiano: podemos nos assustar e empalidecer; podemos nos constranger e enrubescer; ou ainda tremer quando estamos com medo. "Mas do que o homem ri? Ri do que é ridículo, 
diremos. Existem, certamente, outras causas também, mas esta é a mais comum e natural” (Ibidem, p. 41). Bakhtin (1999, p. 57), remontando ao humor no Renascimento, descreve que o riso "tem um profundo valor de concepção do mundo, é uma das formas capitais pela qual se exprime a verdade sobre o mundo na sua totalidade, sobre a história, sobre o homem". Em sua teoria da "carnavalização", Bakhtin (1981, p. 123) defende uma ode ao riso, e elege a paródia como seu elemento basilar. Por meio da sátira e da ironia, questiona-se a realidade, subvertendo-a.

Ainda a partir de Bakhtin (1992, p. 323), podemos entender o conceito de "dialogismo", em que o autor pressupõe que um texto é composto por diversos outros, absorvendo e transformando conteúdos prévios. Seguindo no âmbito do discurso, Kristeva (1974, p. 64) trabalha a "intertextualidade" ao elencar três dimensões do espaço textual: o sujeito (quem escreve), o destinatário (quem recebe) e os textos exteriores (outros conteúdos). Para Kristeva, esses elementos estabelecem um diálogo, de maneira que a palavra pertence ao mesmo tempo ao sujeito e ao destinatário, sendo orientada por uma literatura prévia ou mesmo sincrônica. Dessa forma, compreendemos que cada texto é um cruzamento de outros textos, uma combinação de outros textos. Para Eco (2003, p. 200), é possível que um texto sobreponha códigos de leitura: por meio do "double coding”, tem-se uma leitura mais simples, por um leitor mais "ingênuo”, e outro código mais complexo, para um leitor mais instruído.

Diante das distintas possibilidades discursivas para a comunicação digital explicitadas nesse tópico, analisaremos a página Narcos (Brasil) na rede social Facebook. Inicialmente faremos um relato sobre a ficção, bem como sobre a inserção da empresa de televisão para Internet Netflix no contexto nacional. Pretendemos, por meio da investigação, compreender de que forma a página utiliza humor, ironia e intertextualidade para cativar seu público.

\section{NARCOS NO FACEBOOK}

Fundada em 1997, a empresa estadunidense Netflix ${ }^{1}$ iniciou seus trabalhos ofertando a locação de DVDs on-line: seus assinantes podiam escolher os filmes que pretendiam assistir e em seguida os receberiam em casa pelos correios. O serviço ainda oferecido nos Estados Unidos é a fonte do processo de conhecimento dos hábitos de consumo de seus assinantes, informações tão importantes para o que hoje é o negócio da empresa.

A empresa está presente desde o início de 2016 em 190 países, e seu sucesso comercial deve-se em parte a uma estratégia de negócios baseada em dados coletados por um sistema de algoritmos que revelam o que seus clientes estão assistindo e de que forma (Steel, 2016). Como afirmou o diretor de comunicação da companhia Jonathan Friedland (2012), na ocasião do lançamento da série House of Cards, "nós sabemos o que as pessoas veem no Netflix e somos capazes de entender com precisão quão grande pode ser a audiência de determinado espetáculo baseando-se nos hábitos das pessoas” (Baldwin, 2012). Após quatro anos, House of Cards já tem sua quinta temporada assegurada para

1. Linha do tempo disponível em: http://nflx.it/2fUMWwp. Acesso em: 10 fev. 2016. 
2017, e outros diversos títulos, de diferentes gêneros, foram lançados pela Netflix, como Orange Is the New Black, Bojack Horseman e Narcos.

Produzida nos Estados Unidos, Narcos é ambientada na Colômbia dos anos 1980 e estrelada por um elenco multinacional composto sobretudo por atores e atrizes renomados do audiovisual latino-americano, como o chileno Pedro Pascal e o brasileiro Wagner Moura. O seriado é protagonizado por Boyd Holbrook, ator estadunidense que interpreta Steve Murphy, agente investigativo do Departamento Antinarcóticos dos Estados Unidos (DEA), que assume, por vezes, o papel de narrador da história. $\mathrm{O}$ enredo retrata a ascensão dos cartéis de tráfico de drogas colombianos, tendo como foco a figura do narcotraficante Pablo Escobar.

Narcos foi lançada em 28 de agosto de 2015 e seguiu o molde das estratégias já comuns da produtora e exibidora Netflix para a estreia: disponibilização integral e simultânea de todos os episódios da temporada na plataforma virtual e intensa divulgação nas redes sociais visando fomentar a audiência. Na rede social Facebook, a página Narcos (Brasil) $^{2}$ iniciou suas postagens em julho de 2015, a princípio divulgando a série e informando aos internautas como e quando poderiam assistir aos episódios. Com a estreia da série, as postagens passaram a utilizar mais o conteúdo da trama, e as interações com o público tornaramse mais frequentes (mais de 3 milhões de pessoas curtem a página, em novembro de 2016), como veremos nas postagens reproduzidas e analisadas a seguir.

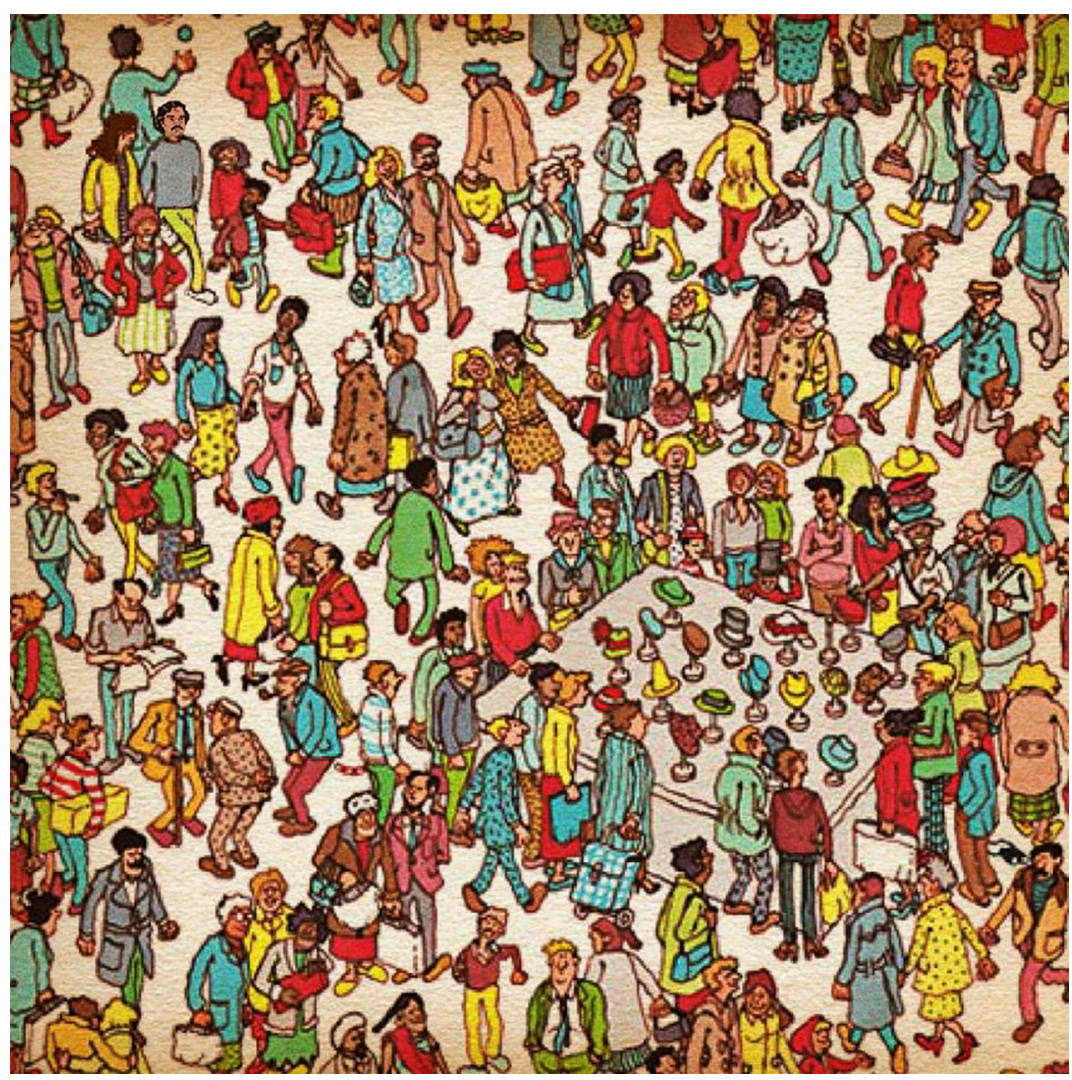

Figura 1. "Onde está o Pablo?”, Narcos Brasil, 2015.

2. Disponível em: https://www.facebook.com/NarcosBrasil/?fref=ts. Acesso em 09/01/2016. 
$\mathrm{Na}$ primeira postagem destacada (Figura 1), foi reproduzido o cenário da série de livros clássica Onde está Wally?, criada por Martin Handford, em uma apropriação bem humorada para o contexto de Narcos. A legenda da postagem “Onde está o Pablo?” faz clara referência intertextual ao título de Wally e também ao contexto da série, visto que em certo momento inicia-se uma busca a Escobar. Na imagem, Pablo está na parte superior esquerda, usando moletom cinza, calça amarela e tênis branco. Os internautas se divertiram em mais de 800 comentários, como: "Achei o Patrón em menos de 5 segundos... \#chupaDEA" e "Você não acha o Patrón, ele que te acha”. Esses dois comentários e diversos outros na postagem indicam a simpatia dos internautas pelo jogo proposto e também a capacidade de produção de conteúdo intertextual, retroalimentando a série. Enquanto o primeiro questiona a atuação do DEA e brinca com a hashtag, o segundo reafirma o controle e o poder de Pablo.

A segunda postagem (Figura 2) utiliza o icônico globo de neve para enviar uma mensagem engraçada de boas-festas aos seguidores da página. No lugar da paisagem natalina ou da figura do Papai Noel está Pablo, envolvo por neve - ou cocaína. Mais de 15 mil curtidas foram registradas nesse post, e destacamos a pergunta de um internauta: “O patrão vai entregar presentes nesse natal?”; e o retorno da página: "Lógico. Nossos duendes já estão em ação".

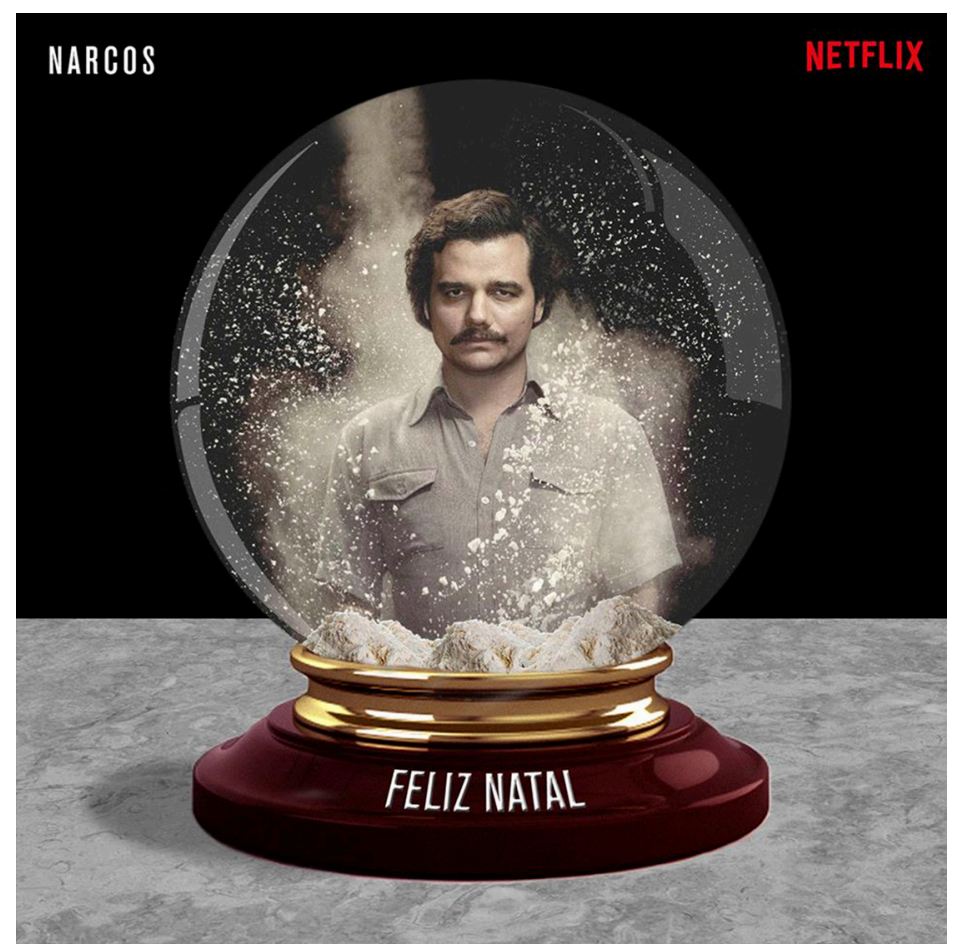

Figura 2. O patrão e a equipe do Cartel desejam um feliz Natal e um próspero ano novo. Narcos Brasil, 2015.

Na terceira postagem (Figura 3), uma ilustração de Escobar encarna um santo (ou o próprio Deus), e o texto diz "Pablo é um santo: ele manda pessoas direto para o céu", além da legenda "Plata o Plomo. Amém” bordão do Escobar que foi firmado na série já no primeiro episódio. Utilizando discurso irônico, que aproxima santidade e traficante, a imagem e o texto tensionam seu papel nobre de ajudar pessoas mais 
pobres e, de forma contraditória, sua postura violenta e impiedosa com aqueles que porventura atrapalham seus negócios. Comentários como "Santo que faz nevar! Kkkkk" reafirmam o tom irônico do texto, referindo-se ao grande volume de cocaína produzido e comercializado.

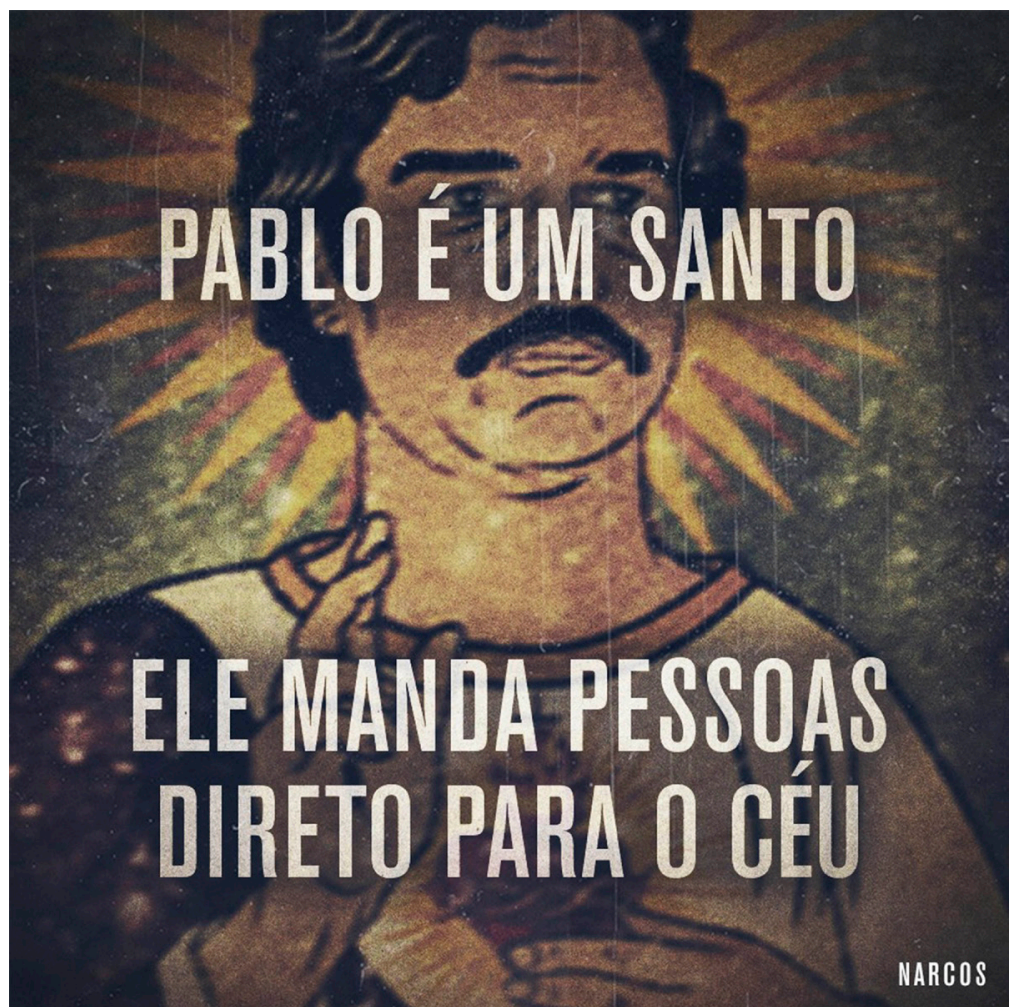

Figura 3. Plata o Plomo. Amém. Narcos Brasil, 2015.

A quarta imagem (Figura 4), postada ainda no período de divulgação da série, traz um aperto de mãos coberto de pó simbolizando um acordo, uma negociação de tráfico. A expressão "Nar-co-no-mi-a" e a legenda "No império da droga não existe crise” apontam a apresentação contextualizada da série diante do cenário político e econômico atual do Brasil.

Na quinta postagem (Figura 5), vê-se uma imagem dividida de um sofá vermelho em um fundo branco e um sofá envelhecido em um cenário escuro. Ao lado do sofá vermelho, leem-se o código de barras com o título "Sofá do IKEA" e o valor de 800 dólares. No lado mais escuro, há o código "Sofá do Pablo Escobar" e o valor de 1 milhão de dólares. A postagem une duas proposições intertextuais: a linguagem publicitária (com o uso de etiquetas, códigos de barra e preço) e, sobretudo, a menção à loja de móveis IKEA; e a referência ao sofá da mãe do Pablo Escobar que serviu de esconderijo para uma grande quantia em dinheiro na série.

A sexta postagem (Figura 6) traz uma imagem de Pablo diante de três estatuetas: plata, oro e plomo. A legenda "Boa noite, paisas. Hoje temos três alternativas" faz clara referência à cerimônia de premiação do Globo de Ouro na qual Wagner Moura concorria ao título de melhor ator em série dramática. Mais de 40 mil internautas curtiram essa postagem, e muitos comentários elogiavam e torciam pelo ator, como: “Oro pro Patrão! Plomo pra quem disser que não!" e "Nada de plata, hoje somente oro! Mercadoria da boa!”. 


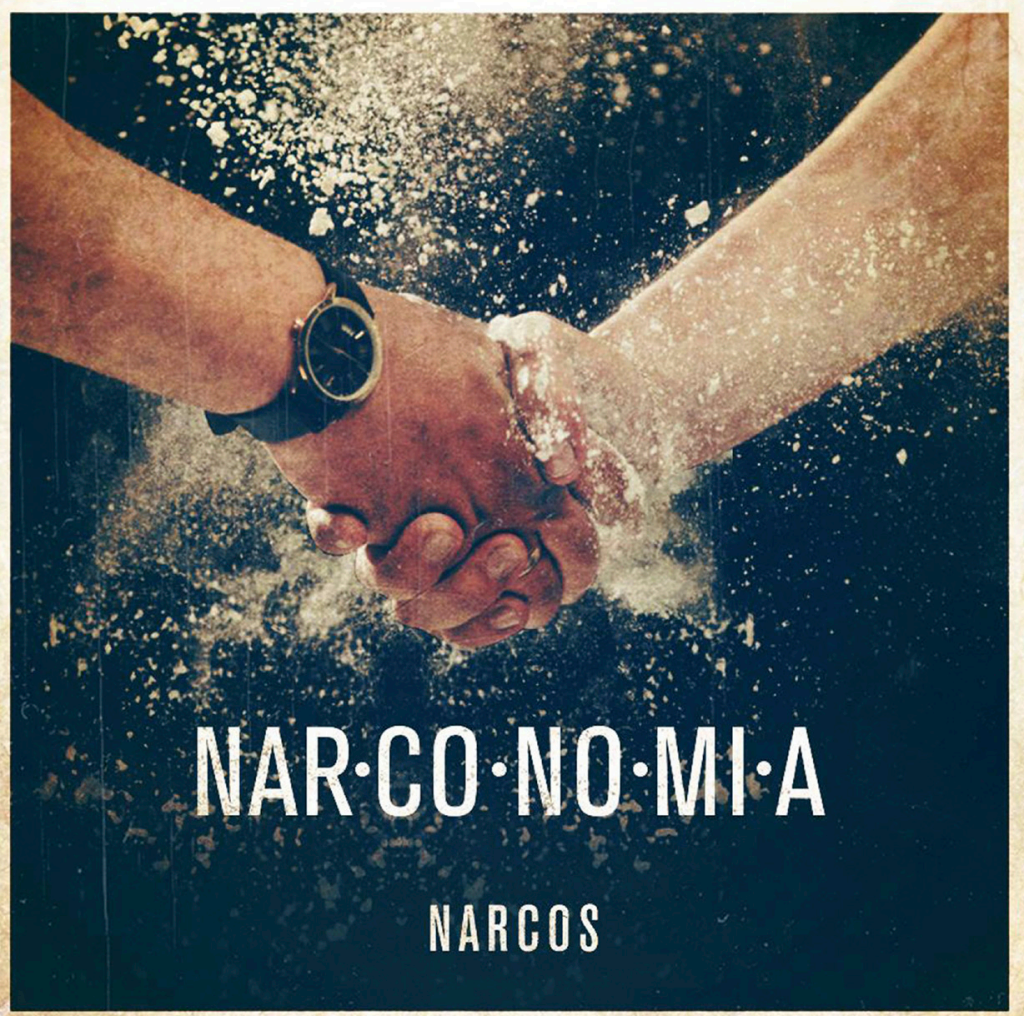

Figura 4. No império da droga não existe crise. Narcos Brasil, 2015.
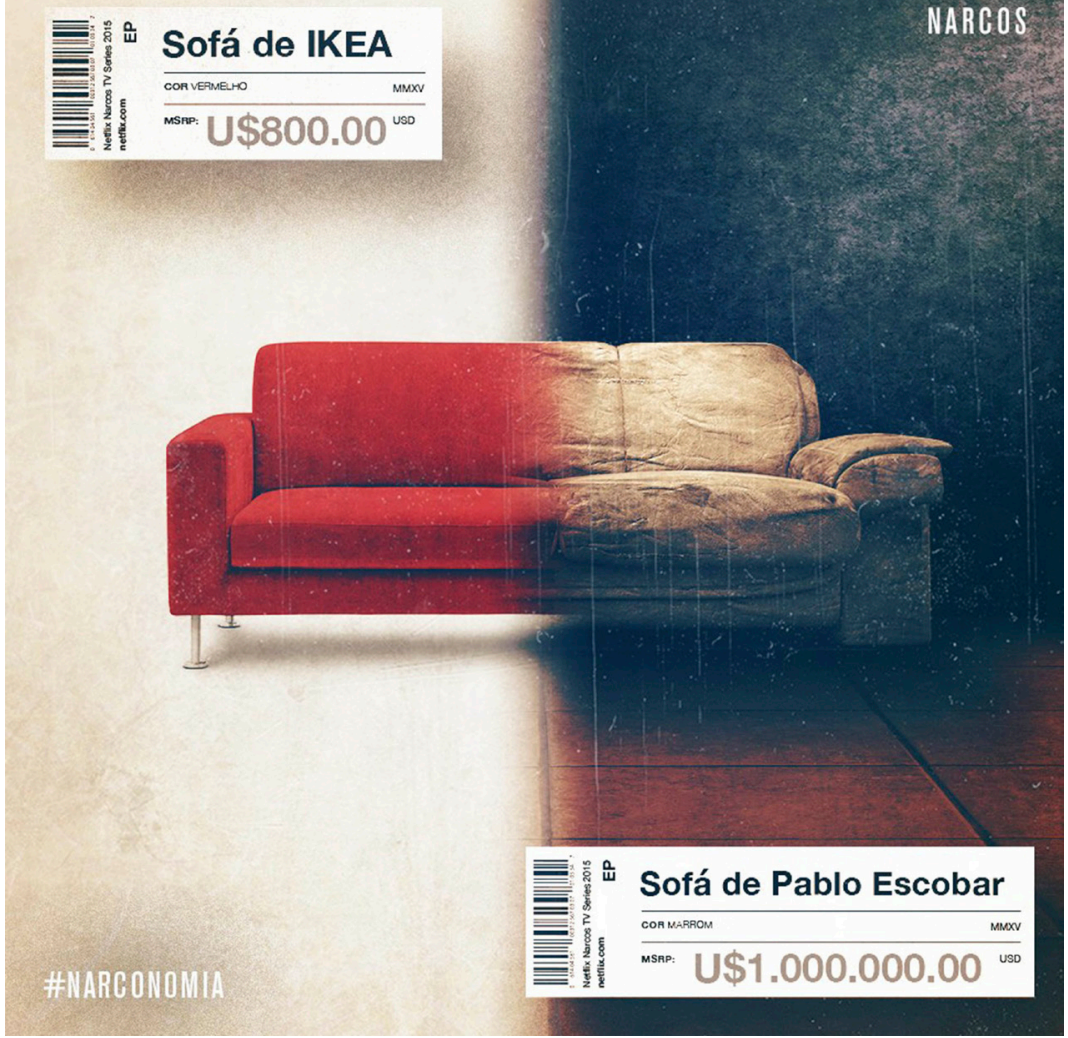

Figura 5. Pablo começou a ter tanto dinheiro vivo, que teve que esconder um milhão de dólares no sofá da mãe. Narcos Brasil, 2015. 


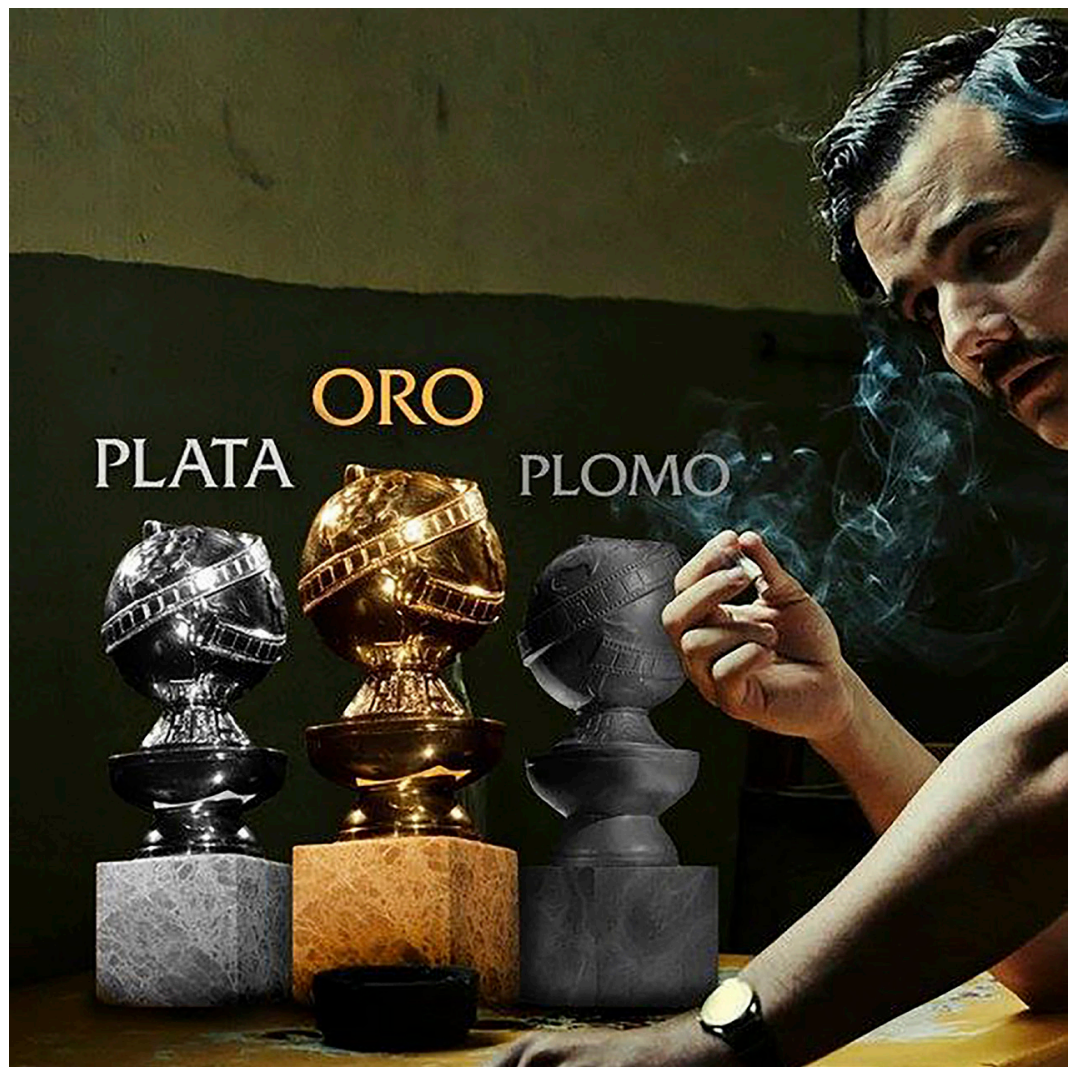

Figura 6. Boa noite, paisas. Hoje temos três alternativas. Narcos Brasil 2015

\section{CONSIDERAÇÕES FINAIS}

Após analisarmos as postagens selecionadas na página Narcos (Brasil) no Facebook, foi possível compreender que sua comunicação estratégica digital utiliza os recursos de humor, ironia e intertextualidades, fundamentada pelos autores resgatados na pesquisa: Propp, Bakhtin e Kristeva, respectivamente. Percebemos também a utilização do double coding mencionado por Eco, tendo em vista a sobreposição dos códigos de leitura e o requisito do repertório específico da série para a plena compreensão dos posts.

A relação que se estabelece com os internautas parte do pressuposto defendido por Jenkins de uma cultura de convergência e, consequentemente, um consumo convergente. A liberação do polo emissor pontuada por Lemos coloca-se como destaque diante de todas as interações proporcionadas pela rede, além da formação de comunidades em torno de interesses em comum, como observam Lévy e Recuero.

Negamos, portanto, a ideia de um consumo estanque e segmentado por mídia. Ao afirmar que não existe substituição de mídias, Santaella é precisa em acreditar numa coexistência e cooperação entre elas. $\mathrm{O}$ consumo de Narcos no Facebook, a produção desses materiais de comunicação e a reapropriação da série e das próprias postagens pelos internautas comprovam a difusão dos antigos limites entre mídias e plataformas.

O público não mais se vincula a uma mídia para consumir determinado produto de entretenimento ou informação. Ele se prende ao conteúdo e o segue por onde for, seja na televisão, na Internet ou 
em conversas de bar. As conexões continuam sendo feitas pelas pessoas com o passar do tempo e com o aperfeiçoamento e a diversificação dos suportes. Os equipamentos modernizam-se, as narrativas encontram novas estruturas, e os conteúdos aproximam-se de novos motes, mas as pessoas permanecem em busca de entretenimento e laços afetivos.

\section{REFERÊNCIAS}

ACSELRAD, M. O humor como estratégia de comunicação. Revista de Comunicação, Cultura e Teoria da Mídia, São Paulo, n. 5, p. 135-144, mar. 2004.

BAKHTIN, M. A cultura popular na Idade Média e no Renascimento: o contexto de François Rabelais. São Paulo: Hucitec,1999.

Estética da criação verbal. São Paulo: Martins Fontes, 1992.

Problemas da poética de Dostoiévski. Rio de Janeiro: Forense Universitária, 1981.

BALDWIN, R. Netflix gambles on big data to become the HBO of streaming. Wired, 29 nov. 2012. Disponivel em: http://bit.ly/2ft3YP4. Acesso em: 31 out. 2016.

BAYM, N. Personal connections in the digital age. Cambridge: Polity Press, 2010.

CASTELLS, M. A Galáxia Internet: reflexões sobre internet, negócios e sociedade. Lisboa: Fundação Calouste Gulbenkian, 2004.

CASTRO, G.; JUNQUEIRA, A. Metodologias de pesquisa em internet. In: PEDEMONTE, D. F. (Coord.). Comunicación aplicada: teoria y método. Salamanca: Comunicación Social Ediciones y Publicaciones, 2014. p. 155-177.

CASTRO, G. Entretenimento, sociabilidade e consumo nas redes sociais: cativando o consumidor-fã. Revista Fronteiras - Estudos Midiáticos, São Leopoldo, v. 14, n. 2, p. 133-140, ago. 2012.

ECO, U. Ironia intertextual e níveis de leitura. In: Ensaios sobre a literatura. Rio de Janeiro: Record, 2003. p. 199-218.

FORD, S. Listening and empathizing: advocating for new management logics in marketing and corporate communications. 2014. Disponivel em: http://bit.ly/2eg0d20. Acesso em: 20 dez. 2015

JENKINS, H.; GREEN, J.; FORD, S. Cultura da conexão: criando valor e significado por meio da mídia propagável. São Paulo: Aleph, 2014

JENKINS, H. Cultura da convergência. São Paulo: Aleph, 2009.

KRISTEVA, J. Introdução à semanálise. São Paulo: Perspectiva, 1974.

LEMOS, A. C. Cibercultura: alguns pontos para compreender a nossa época. In: LEMOS, A.; CUNHA, P. (Org.). Olhares sobre a cibercultura. Sulina: Porto Alegre, 2003. p. 11-23.

LÉVY, P. O ciberespaço e a economia da atenção. In: PARENTE, André (Org.). Tramas da rede. Porto Alegre: Sulina, 2004, p. 174-188. 34,2001

A conexão planetária: o mercado, o ciberespaço, a consciência. São Paulo: Editora

PROPP, V. Comicidade e riso. São Paulo: Ática, 1992.

RECUERO, R. Redes sociais na internet. Porto Alegre: Sulina, 2009.

SANTAELLA, L. Cultura e artes do pós-humano: da cultura das mídias à cibercultura. São Paulo: Paulus, 2006

Da cultura das mídias à cibercultura: o advento do pós-humano. FAMECOS, Porto Alegre, n. 22, p. 23-32, 2003.

SIBILIA, P. O show do eu: a intimidade como espetáculo. Rio de Janeiro: Nova Fronteira, 2008

STEEL, E. At CES, Netflix adds over 130 countries to streaming servisse. The New York Times, 6 jan. 2016. Disponível em: http://nyti.ms/2fayDTd. Acesso em: 31 out. 2016. 